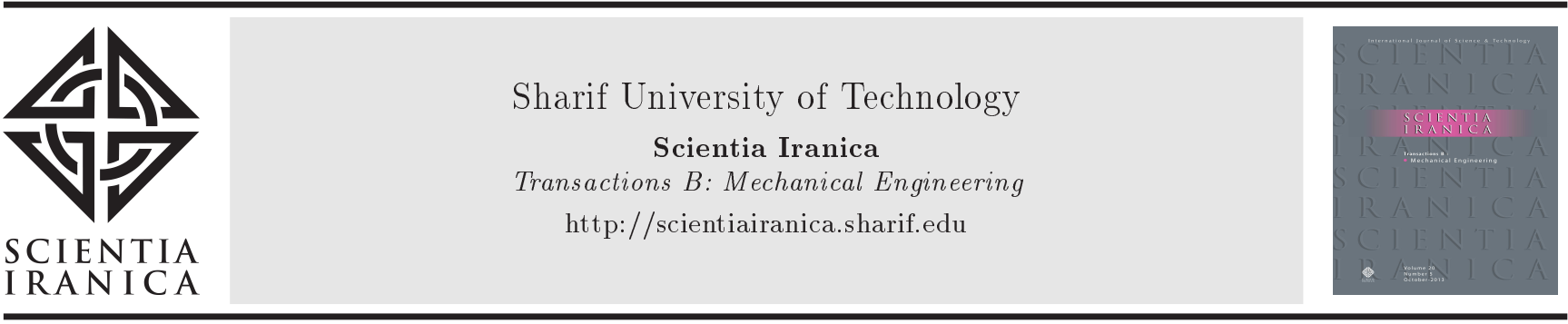

\title{
Global optimization for cross-domain aircraft based on kriging model and particle swarm optimization algorithm
}

\author{
Y.-L. Chen ${ }^{a}, *$ J.-C. Qin ${ }^{a}$, H.-P. Sun ${ }^{a}$, T. Shang ${ }^{b}$, X.-G. Zhang ${ }^{a}$, and Y. Hu ${ }^{a}$ \\ a. School of Mechanical and Aerospace Engineering, Jilin University, Changchun 130022, China. \\ b. College of Mechanical and Electrical Engineering, Jiaxing University, Jiaxing 314001, China. \\ Received 17 April 2018; received in revised form 12 July 2019; accepted 11 November 2019
}

\author{
KEYWORDS \\ Cross-domain aircraft; \\ Kriging model; \\ PSO algorithm; \\ Orthogonal test; \\ Global optimization.
}

\begin{abstract}
In order to further enhance and extend the capabilities and efficiency of current aircrafts, a new type of water-air cross-domain aircraft was herein proposed. The fixedwing aircrafts' working system was the source of inspiration for designing this new type of water-air cross-domain aircraft. This new type of water-air aircraft has extra tandem ducted coaxial rotors and tail ducted propulsion system, and is driven by a hybrid power system. Due to its layout situation, the fluid underwater characteristics was especially analyzed based on Computational Fluid Dynamics (CFD) simulation experiments, which mainly aimed at the thrust force characteristics influenced by different layout parameters of tail ducts and different rotational velocities. In order to figure out the optimal layout which can reach the best underwater performance, a global layout optimization was accomplished using the result of the previous studies. The studies employed an optimization method based on Particle Swarm Optimization (PSO) algorithm with the compensation of orthogonal test and Kriging model to decrease computational complexity and improve interpolation accuracy. The global optimal layout solution was finally obtained and validated to insure reasonable accuracy through extra simulation experiments, and the proposed optimization method was also proved to be effective.
\end{abstract}

(C) 2021 Sharif University of Technology. All rights reserved.

\section{Introduction}

During the World War II, the idea of designing a combined weapon, representing the capabilities of both bomber and submarine weapons was proposed, but due to the limitation of technology in that period, it finally failed [1]. However, after decades and following the technology advancement, the ambition

\footnotetext{
*. Corresponding author. Tel.: +860431 88777273
} E-mail address: chenyanli@jlu.edu.cn. (Y.-L. Chen)

doi: $10.24200 /$ sci. 2019.50814 .1886 to develop water-air amphibious aircrafts, which would effectively improve the working space and adaptability to environment and would enhance the development of applications, came up again [2].

Nowadays, one successful design strategy for cross-domain aircrafts is bio-inspired method, which combines the features of aircrafts and amphibious creatures using morphing structures and advanced materials. Gao and Techet in Massachusetts Institute of Technology (MIT) proposed a robotic flying fish with the pectoral fins made up of polyurethane coated nylon [3]. Fabian and Techet in MIT [4] and Liang et al. in Beihang University [5] respectively designed 
gannet-inspired submersible aircrafts with morphing fixed wings which can be folded during the water entry process for further decrease of underwater drag. By imitating flying squids, Siddall et al. in Imperial College London added a jet propeller to gannet-like amphibious aircraft to improve the efficiency of waterexit process $[6,7]$. Chen et al. in Harvard University presented a hybrid aerial-aquatic micro-robot inspired by flapping-wing insects, which was driven by a pair of piezoelectric actuators with extra buoyant adjustment device based on electrochemical reactions $[8,9]$.

Another typical design thought is based on multirotor technology, which has been widely utilized in Unmanned Aerial Vehicles (UAVs) and Remotely Operated Vehicles (ROVs). Alzu'bi et al. in Oakland University improved traditional quadrotors with additional water pumps for buoyancy and underwater depth control $[10,11]$. Based on X-4 configuration, Maia et al. in Rutgers University utilized dual air rotors in each vehicle arm with a column gap between the top and bottom motors, which highly improved effective lift force [12-14]. Brazilian researchers Drews et al. changed bottom 4 air rotors into water rotors in order to obtain better underwater performance $[15,16]$. Feng et al. in Air Force Engineering University improved Drews's design by importing two X-4 frames with replaceable column, due to which the height between two layers of rotors can be adjusted during the transmedia process $[17,18]$. Lu et al. in Shanghai Jiao Tong University proposed a design concept combined with quadrotors and underwater gliders, which extended working endurance [19].

Obviously, the bio-inspired designs require high implementation cost, and the open-frame multi-rotor designs show unfriendly hydrodynamic performances. Therefore, a type of water-air cross-domain aircraft with duct propulsion system was herein proposed. The fluid underwater characteristics were especially analyzed, since the layout was mainly based on the airplanes. In order to figure out the optimal layout which could lead to better underwater performance, a Kriging-based Particle Swarm Optimization (PSO) algorithm was employed for global optimization process, which finally resulted in an optimal solution with satisfying performance.

\section{System architectures and working principles}

\subsection{System architectures}

The proposed ducted cross-domain UAV can be considered as a mixture of a fixed-wing aircraft with tandem ducted coaxial propellers and a submarine, and the layouts of the body, which consists of four ducts, two airtight cabin doors and a water storage, is shown in Figure 1.

In the flying condition, the lift force in the air

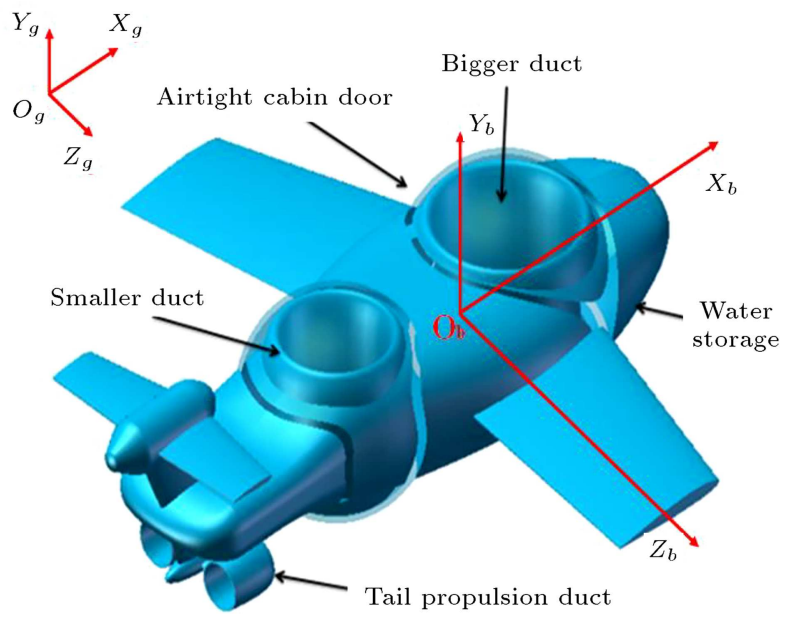

Figure 1. The layout of the aircraft and the coordinate systems.

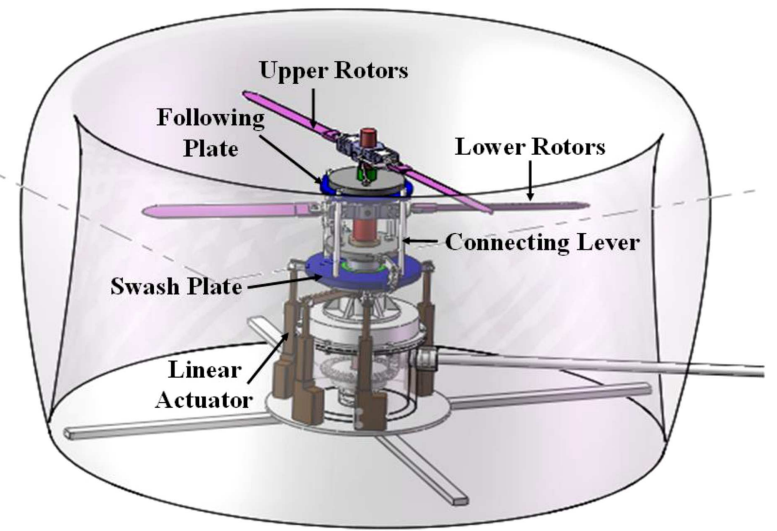

Figure 2. The detailed architecture of coaxial rotors in the ducts.

is mainly provided by coaxial rotors in bigger and smaller ducts, which are also called main ducts, and the flight direction can be controlled by blade pitch adjustment devices which are installed on each duct (Figure 2). The swash plates driven by linear actuators at bottom directly control the blade pitches of upper rotors. When the blade pitch angles are changed by forward flight directions, the upper rotors will tilt forward, which compels the rotating cone to tilt as well and generates forward aerodynamic forces. In the underwater condition, the architecture of airtight cabin doors is herein adopted to seal the bigger and smaller ducts. The tail propulsion ducts are designed to provide the thrust force for surging and underwater yawing motions. The water storage can be considered as depth control system; its mass changes by storing different quantity of water, which will create a pitching torque in $X_{b} O Y_{b}$ plane with buoyancy.

Compared with the single rotor architecture, the coaxial rotors architecture consumes less power to reach the same lift force requirements. Furthermore, it can help to keep the balance of the whole system by 
offsetting a pair of opposite torques caused by upper and lower rotors as well as by compacting the entire duct architecture. Both of the main ducts share the same architectures, and they all adopt NACA 4415 airfoil profile. The tail pro-pulsion ducts adopt the water rotors of 4415 profile, which can work better in the under-water condition. And the two side-wings adopt NACA 2412 airfoil profile according to their features of bend and tension and the coordination with the shape design, which include extra equip of former and latter rafters, spars and rips.

As for the power source, a hybrid system with fuel engine and electromotor is applied: fuel engine mainly works in the air and the electromotor works underwater. There are two output shafts of the torque divider gearbox which is the core component of the system.

The input shaft is connected with the engine through clutch 1 :

- One of the output shaft directly transfers the power to the differential gear box which drives the coaxial air rotors in the main ducts;

- The other output shaft attaches the electric generator through clutch 2, which will charge the battery pack for underwater use.

The battery provides electric power to the electromotor, the later drives the water rotors of tail ducts and the water storage located on the head of the aircraft, which follow the directions from the controller. The schematic of the power system is depicted in Figure 3.

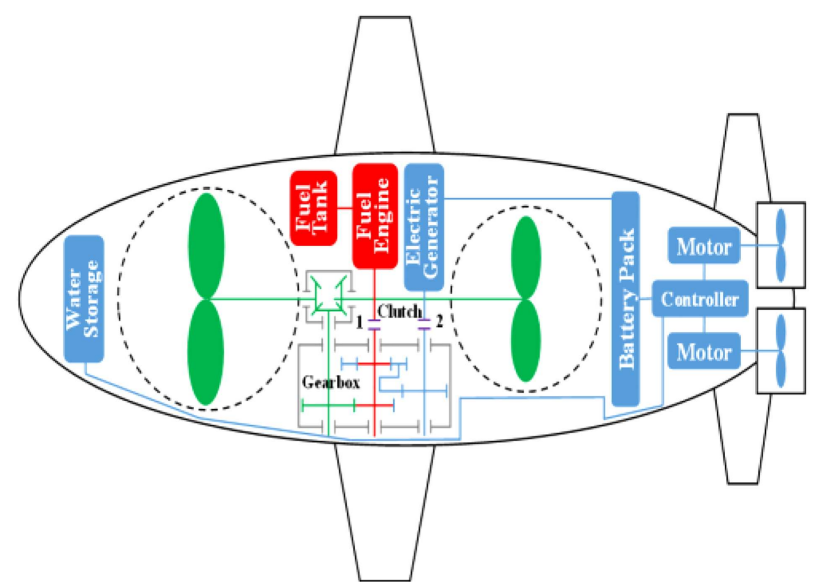

Figure 3. The schematic of the hybrid power system.

\subsection{Working principles}

When the UAV works in the air, the lift force is all provided by the main ducts and the flight attitude is controlled by the blade pitch adjustment devices of the ducts with the open doors airtight. Under this condition, the whole system is powered by fuel engine with both clutches engaged. When it flies near the water, the airtight doors soon close tightly with the engine shut down while the system will be powered by the battery pack with both clutches cut off. While it is diving into water, the water storage opens itself and starts to store water to change its self-mass. Meanwhile, the tail propulsion ducts start to provide the thrust force for the UAV and control the yawing directions with the adjustment of their rotational velocity.

\section{Mathematical models}

Different architectures of ducts and couplings of lift forces bring great difficulties to build the dynamic models of the UAV, therefore the main tasks of the analysis and simulation is to select a suitable coordinate system and establish its dynamic model.

\subsection{The selection of the coordinate system}

The coordinate systems including the ground one and the body one are selected as shown in Figure 1 in which $O_{g}$ is any point on the ground; $X_{g}$ axis represents the flight direction; $Y_{g}$ axis represents the vertical direction and $Z_{g}$ axis is obtained by right-hand principles. $O_{b}$ is the barycenter of the body and the directions of coordinate axes are shown in the schematic. The angle around $Z_{b}$ axis is the pitch angle $\theta$; the angle around $Y_{b}$ axis is the yawing angle $\varphi$ and the angle around $X_{b}$ axis is the rolling angle $\gamma$.

According to the rule of coordinate system transformation, the transition matrix from the ground coordinate system to the body one is obtained by Eq. (1) as shown in Box I.

\subsection{The establishment of the dynamic model}

The ducted water-air cross-domain UAV is regarded as an ideal rigid body, and its motion equations are obtained from the movement and rotation dynamic equations of the barycenter.

The translational dynamic equations of the barycenter are shown as follows:

$$
\left[\begin{array}{l}
X \\
Y \\
Z
\end{array}\right]=\left[\begin{array}{ccc}
\cos \theta \cos \phi & \sin \theta & -\cos \theta \sin \phi \\
-\cos \gamma \sin \theta \cos \phi+\sin \gamma \sin \phi & \cos \gamma \cos \theta & \cos \gamma \sin \theta \sin \phi+\sin \gamma \cos \phi \\
\sin \gamma \sin \theta \cos \phi+\sin \gamma \cos \gamma & -\sin \gamma \cos \theta & -\sin \phi \sin \gamma \sin \theta+\cos \gamma \cos \phi
\end{array}\right]\left[\begin{array}{c}
X_{D} \\
Y_{D} \\
Z_{D}
\end{array}\right]
$$




$$
\begin{aligned}
& m\left(\frac{\mathrm{d} V_{x}}{\mathrm{~d} t}+V_{z} w_{y}-V_{y} w_{z}\right)+m g \sin \theta=F_{X}, \\
& m\left(\frac{\mathrm{d} V_{y}}{\mathrm{~d} t}+V_{x} w_{z}-V_{z} w_{x}\right)+m g \cos \theta \cos \gamma=F_{Y}, \\
& m\left(\frac{\mathrm{d} V_{\mathrm{z}}}{\mathrm{d} t}+V_{y} w_{x}-V_{x} w_{y}\right)+m g \cos \theta \sin \gamma=F_{Z},
\end{aligned}
$$

where, $m$ represents the mass of the UAV; $V$ and $w$ represent the absolute velocity and rotational angular velocity in the body coordinate system relative to the ground coordinate system and $F$ represents the aerodynamic force.

The rotational dynamic equations of its barycenter are shown as follows:

$$
\begin{aligned}
& I_{x} \frac{\mathrm{d} w_{x}}{\mathrm{~d} t}+w_{y} w_{z}\left(I_{z}-I_{y}\right)+\left(w_{x} w_{z}-\frac{\mathrm{d} w_{y}}{\mathrm{~d} t}\right) I_{x y}=\sum M_{x} \\
& I_{\mathrm{y}} \frac{\mathrm{d} w_{y}}{\mathrm{~d} t}+w_{x} w_{z}\left(I_{x}-I_{z}\right)+\left(w_{y} w_{z}-\frac{\mathrm{d} w_{x}}{\mathrm{~d} t}\right) I_{x y}=\sum M_{y} \\
& I_{z} \frac{\mathrm{d} w_{z}}{\mathrm{~d} t}+w_{x} w_{z}\left(I_{y}-I_{x}\right)+\left(w_{y}^{2}-w_{x}^{2}\right) I_{x y}=\sum M_{z}
\end{aligned}
$$

where, $I$ represents the inertia moment of the body mass to each axis; $I_{x v}, I_{v z}$, and $I_{z x}$ are the products of inertia, and $M$ represents the moment acting on the aircraft.

The relationship between the rotational angular velocity and Euler angular velocity in the body coordinate system is depicted as follows:

$$
\begin{aligned}
{\left[\begin{array}{l}
w_{x} \\
w_{y} \\
w_{z}
\end{array}\right]=} & T_{x}(\gamma) T_{z}(\theta) T_{y}(\phi)\left[\begin{array}{l}
0 \\
\dot{\phi} \\
0
\end{array}\right] \\
& +T_{x}(\gamma) T_{z}(\theta)\left[\begin{array}{l}
0 \\
0 \\
\dot{\theta}
\end{array}\right]+T_{x}(\gamma)\left[\begin{array}{l}
\dot{\gamma} \\
0 \\
0
\end{array}\right] \\
= & {\left[\begin{array}{cc}
\dot{\phi} \cos \theta \cos \gamma+\dot{\theta} \sin \gamma \\
-\dot{\phi} \sin \gamma \cos \theta+\dot{\theta} \cos \gamma
\end{array}\right] } \\
= & {\left[\begin{array}{ccc}
1 & \sin \theta & 0 \\
0 & \cos \gamma \cos \theta & \sin \gamma \\
0 & -\sin \gamma \cos \theta & \cos \gamma
\end{array}\right]=\left[\begin{array}{c}
\dot{\gamma} \\
\dot{\phi} \\
\dot{\theta}
\end{array}\right] . }
\end{aligned}
$$

\section{Fluid underwater characteristics analyses}

The whole layout of the cross-domain UAV is based on fixed-wing aircrafts with tandem ducted coaxial propellers, therefore it is more necessary to analyze its underwater characteristics rather than aerial ones. The underwater thrust force is mainly influenced by the lateral distance and longitudinal distance of two tail ducts and their rotational velocity. In this chapter, the fluid underwater characteristics analyses, which mainly aim at the impact factors mentioned above, are presented.

\subsection{The model of the body with tail ducts}

As mentioned in the section of working principles, the main ducts in the middle of the aerial vehicle will be tightly sealed when UAV works underwater, therefore the details of the main ducts can be simplified when designing the underwater model. The schematic of the lateral distance $d$ and longitudinal distance $h$ are both depicted in Figure 4.

\subsection{Mesh generation and boundary condition selection}

4.2.1. Mesh generation

With the help of $A N S Y S I C E M C F D$ [20], the meshes are generated. In order to reduce the number of the meshes without reducing the quality of the meshes or increasing the size of each single mesh, the mesh model needs tailoring. The body of the UAV is perfectly symmetrical about the middle plane so that it is feasible to only generate the mesh of a half body as shown in Figure 5(a). Based on this designed mesh the simulation result of the whole body can be calculated. The mesh of the tail rotors is also generated in Figure 5(b) to analyze the effects of the tail duct distance and tail rotor rotational velocity on the thrust force.

After generating the mesh of the main parts of

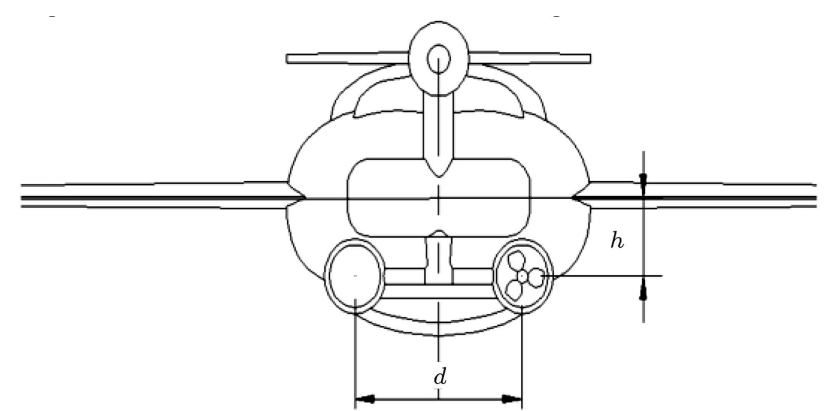

Figure 4. The schematic of the lateral and longitudinal distance.

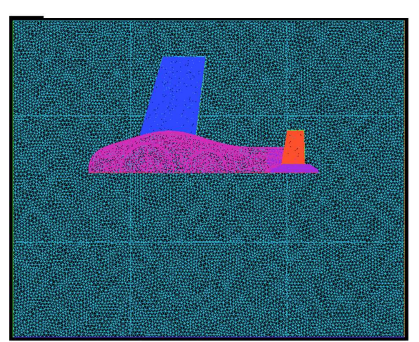

(a) The mesh of the body

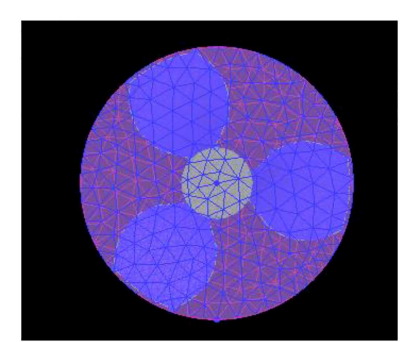

(b) The mesh of the rotor
Figure 5. The mesh generation. 


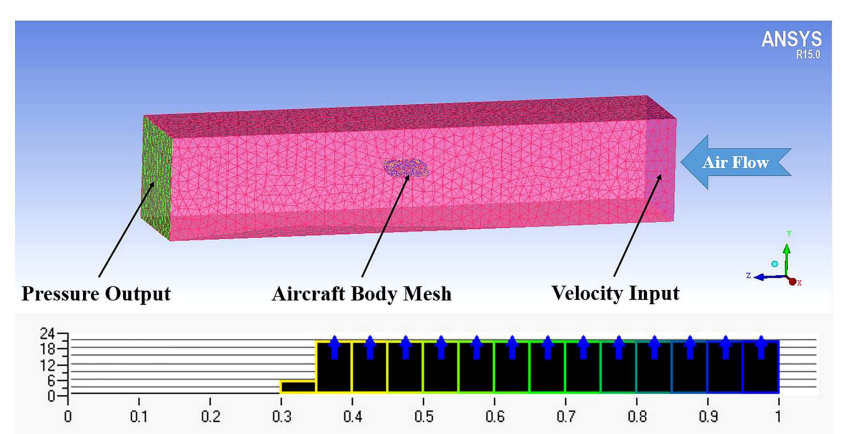

Figure 6. The inspection of the assembly building's mesh.

the UAV, the meshes of each rotor are assembled into the mesh of body. A much larger calculation zone is selected to simulate the fluid environment, the mesh of which is provided in the same way. In order to simplify the calculation, a smaller cubic structure with small meshes, which properly encases the mesh assembly, is generated. Then it is assembled into a bigger cubic structure with bigger meshes. All of the above described meshes constitute the assembly building which is used for further simulation by Fluent.

Before simulation, this assembly building needs testing and Integrated Computer Engineering and Manufacturing Code for Computational Fluid Dynamics (ICEMCFD) can also help delete the improper meshes and smooth the correct meshes automatically during the test. As shown in Figure 6, most meshes are satisfying for further operations with their quality above 0.3 , which is a threshold proved to be acceptable by common solvers in Fluent.
Besides, the principle to select the minimum size of each mesh is to select the superficial area of each surface. If the primary selection of the minimum size does not lead to a satisfactory test result, then a new mesh generation is needed.

\subsubsection{Boundary condition selection}

The Fluent's boundary conditions are selected as shown in Table 1.

\subsection{Flow field characteristics analyses}

As it is clear from the partial enlargement of pathlines' image (Figure 7), the directions of streamlines become irregular, when the water flow pass through the body. This disturbance is more obvious, especially near the tail part of the body.

From the body's pressure contours (Figure 8), high-pressure areas are formed near the front parts of body, in the joints between two airtight doors and the body, on the front parts of the wings and on the front lips of the tail propulsion ducts, because of the resistance created by water.

\subsection{Fluid characteristics analyses}

4.4.1. The effects of different lateral distances of tail ducts on thrust force

When the UAV works underwater, its working condition is supposed to be horizontal navigation with the front and tail wings fixed relative to the body. Keep the rotational velocity of the rotors at $500 \mathrm{rpm}$ and $1000 \mathrm{rpm}$ as well as the longitudinal distance at 200 $\mathrm{mm}$, and change the lateral distances into $280 \mathrm{~mm}$, $320 \mathrm{~mm}, 360 \mathrm{~mm}, 400 \mathrm{~mm}$ and $440 \mathrm{~mm}$ to finish the

Table 1. The selection of boundary conditions.

\begin{tabular}{|c|c|}
\hline Boundary conditions & Settings \\
\hline Unit conversion & Transform $m$ into $\mathrm{mm}$ \\
\hline Material selection & Select water flow as the fluid \\
\hline Input/output selection & $\begin{array}{l}\text { Take the negative direction } X_{b} \text { of axis as the velocity input and take the positive } \\
\text { direction of } X_{b} \text { axis as the pressure output, which have already labeled in Figure } 6 \\
\text { As for the density-increasing area of the body shown in the figure, } \\
\text { it stands for the mesh assembly of the body, rotors and the smaller cubic structure }\end{array}$ \\
\hline Computational domain setting & $\begin{array}{l}\text { Select water as the working medium, and set the rotor state as moving wall } \\
\text { rotation, which will never rotate relative to the neighbor area }\end{array}$ \\
\hline Interface selection & $\begin{array}{l}\text { The interfaces area between rotational rotors and the UAV body was setting } \\
\text { as computation domain; the information transmission between the rotating } \\
\text { rotor and the aircraft body is increased by increasing the volume density } \\
\text { of the computational domain }\end{array}$ \\
\hline Solver selection & $\begin{array}{l}\text { Select the pressure solver, which is widely applied for } \\
\text { incompressible fluid with smaller flow velocity }\end{array}$ \\
\hline
\end{tabular}




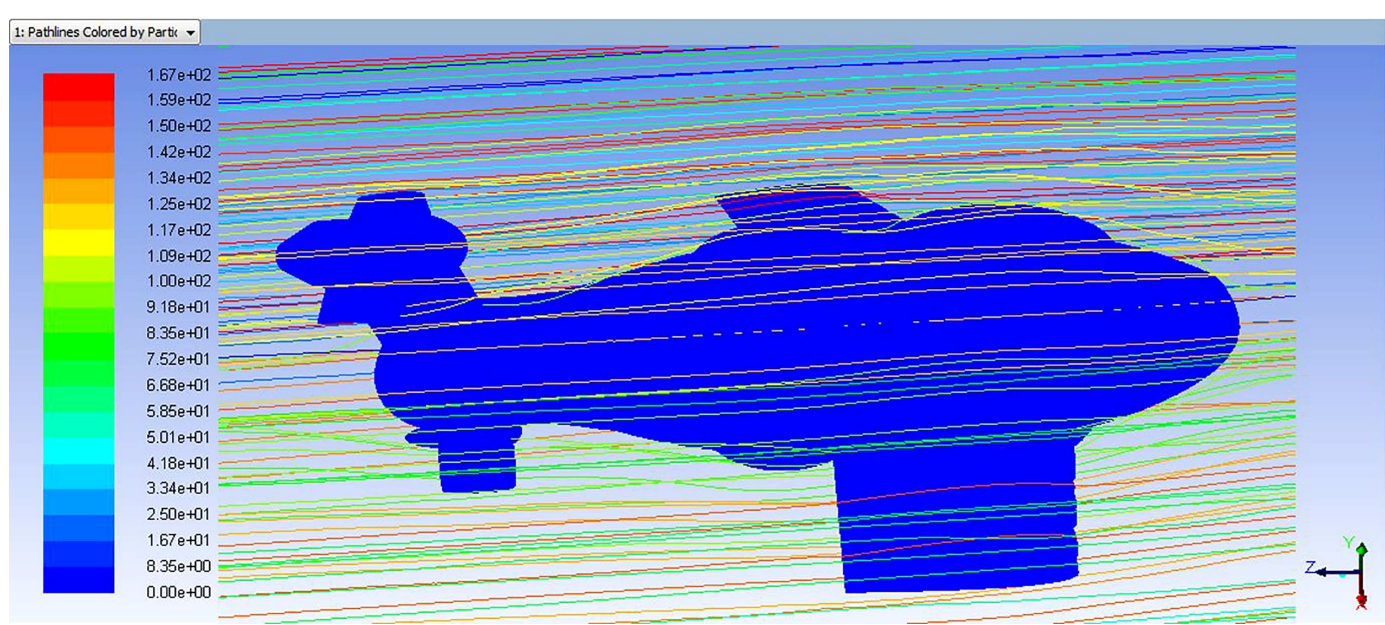

Figure 7. The partial enlargement of water pathlines's image.

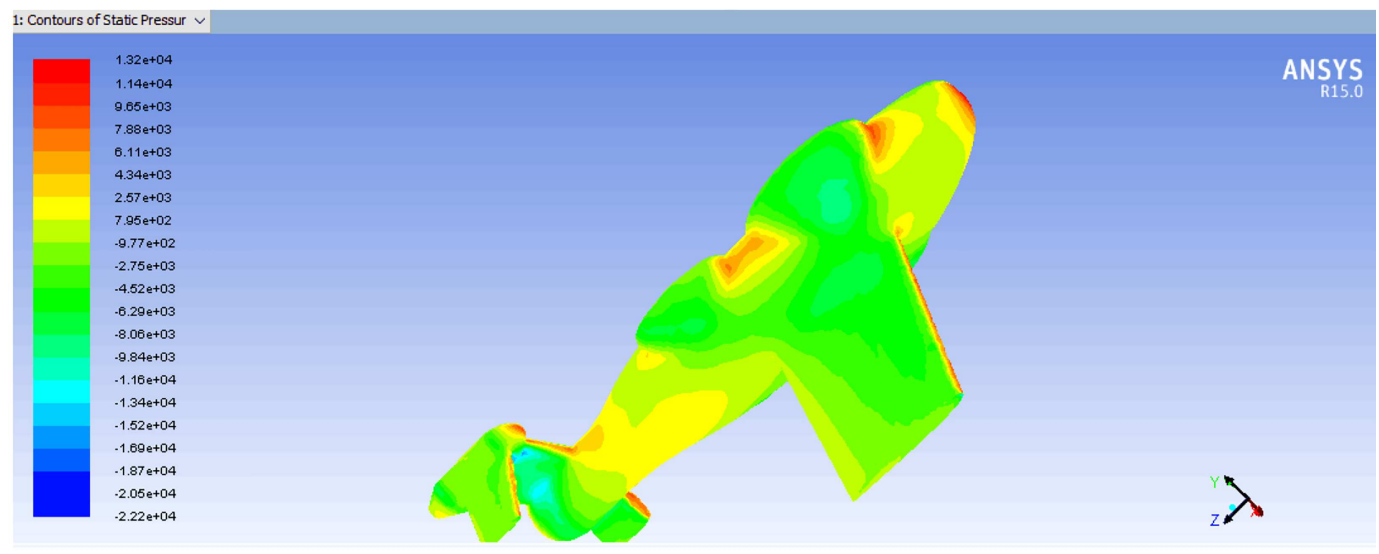

Figure 8. The pressure contours of the body.

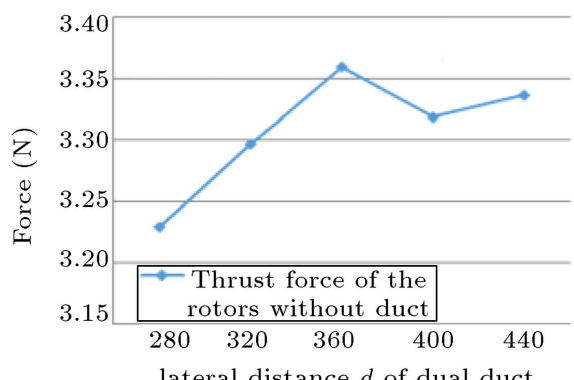

lateral distance $d$ of dual duct (a) The thrust force of the rotors

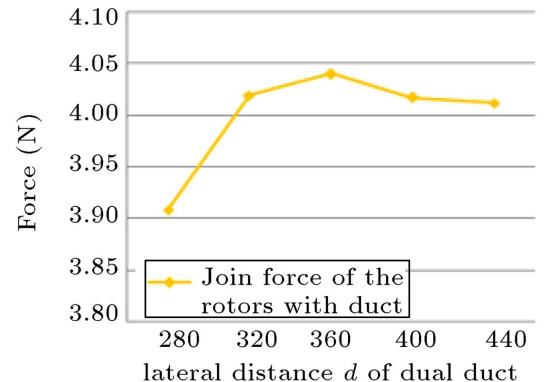

(b) The join force of the rotors in ducts

Figure 9. The thrust force with a rotational velocity at $500 \mathrm{rpm}$.

simulation and the analysis of the fluid underwater characteristics in Fluent. The changes of the thrust forces impacted by the lateral distance are presented in Figures 9 and 10.

It is obviously seen in Figures 9 and 10 that the forces first increase and then decrease with the increase of the lateral distance, and ducts can improve the thrust force for the UAV. As the rotational velocity grows, the forces also grow, and the join force reaches its maximum level when the selected lateral distance is $360 \mathrm{~mm}$.

\subsubsection{The effects of different longitudinal distance of} tail ducts on thrust force

The rotational velocity of the rotors was kept at $500 \mathrm{rpm}$ and $1500 \mathrm{rpm}$ and the lateral distance at $280 \mathrm{~mm}$, and then the longitudinal distances of two tail ducts changed into $180 \mathrm{~mm}, 190 \mathrm{~mm}, 200 \mathrm{~mm}$, $210 \mathrm{~mm}$ and $220 \mathrm{~mm}$ to analyze the fluid underwater characteristics in Fluent and to select the most suitable longitudinal distance. The changes of the thrust forces impacted by the longitudinal distance are shown in Figures 11 and 12 . 


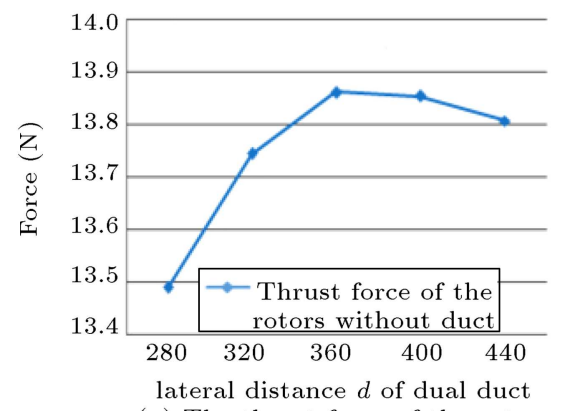

(a) The thrust force of the rotors

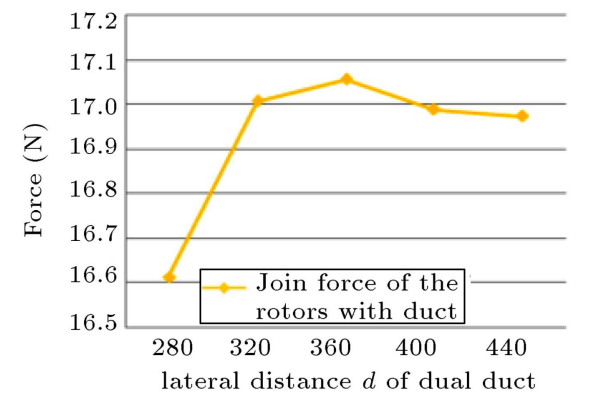

(b) The join force of the rotors in ducts

Figure 10. The thrust force with a rotational velocity at $1000 \mathrm{rpm}$.

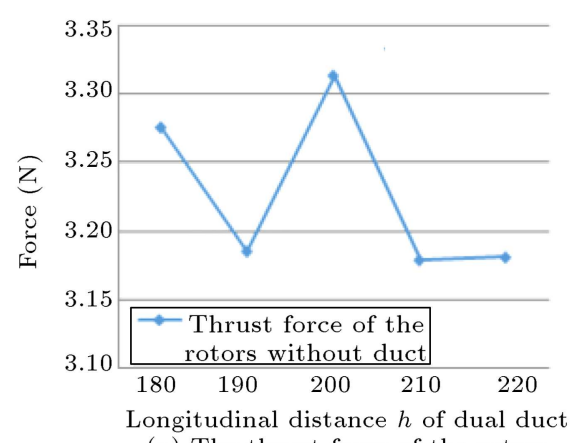

(a) The thrust force of the rotors

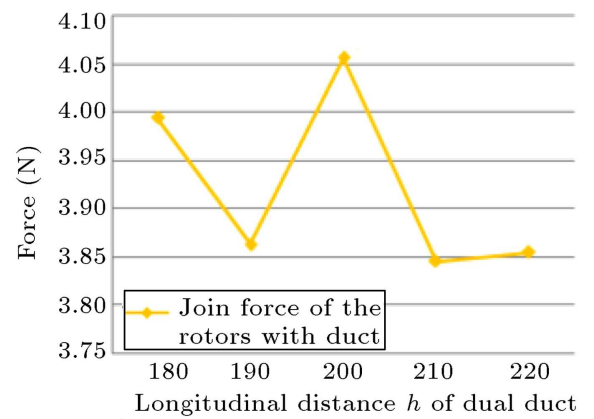

(b) The join force of the rotors in ducts

Figure 11. The thrust force with a rotational velocity at $500 \mathrm{rpm}$.

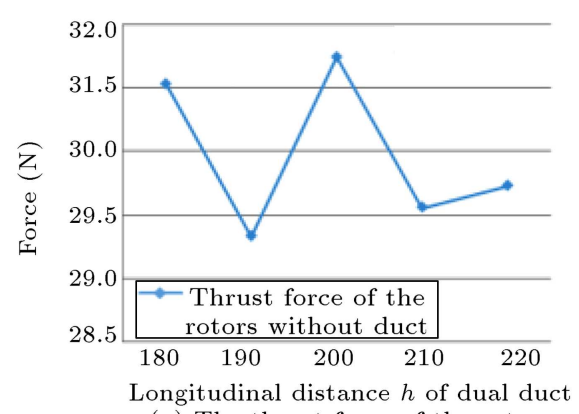

(a) The thrust force of the rotors

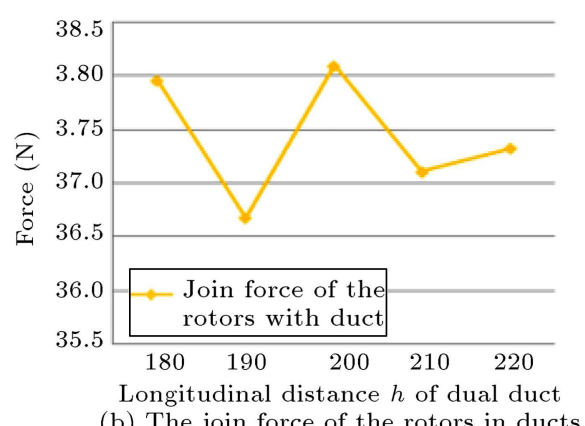

(b) The join force of the rotors in ducts

Figure 12. The thrust force with a rotational velocity at $1500 \mathrm{rpm}$.

It is clearly shown in Figures 11 and 12 that the forces change irregularly with the increase of the longitudinal distance, and the ducts also improve the thrust force for the UAV. As the rotational velocity grows, the forces also grow, and the join force reaches its maximum level when the selected longitudinal distance is $200 \mathrm{~mm}$, the value representing one-half of the height of the entire body.

\subsubsection{The effects of different rotational velocity on the characteristics of rotors}

The head direction of the UAV is supposed to be the positive direction and the rotor side that faces this positive direction is considered as to be the face side. The lateral distance is kept at $360 \mathrm{~mm}$ and the longitudinal distance at $200 \mathrm{~mm}$; then the rotational velocities are changed into $500 \mathrm{rpm}, 1000 \mathrm{rpm}, 1500 \mathrm{rpm}, 2000 \mathrm{rpm}$, and $2500 \mathrm{rpm}$. The pressure contours with different rotational velocities are shown in Figure 13.

It is clearly shown in Figure 13 that the pressures of the face side and the reverse side grow larger as the rotational velocity rises. The increase of the water flow velocity relative to the rotors leads to this phenomenon. The pressure of the reverse side is always larger than that of the face one due to the flow velocity differences between these two sides, which also provide the thrust force when the UAV navigates underwater.

The longitudinal distance is kept at $200 \mathrm{~mm}$ as well as the lateral distance at $280 \mathrm{~mm}$ and $360 \mathrm{~mm}$; the rotational velocities are also changed into $500 \mathrm{rpm}$, $1000 \mathrm{rpm}, 1500 \mathrm{rpm}, 2000 \mathrm{rpm}$, and $2500 \mathrm{rpm}$. The force characteristics are obtained as shown in Figure 14. 
The face side

The reverse side

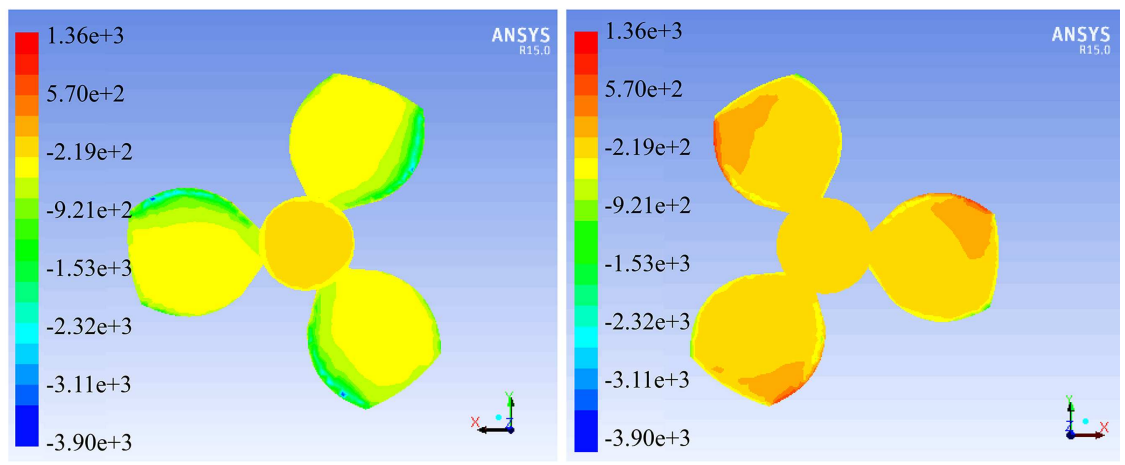

(a) The rotational velocity at $500 \mathrm{rpm}$

The face side

The reverse side

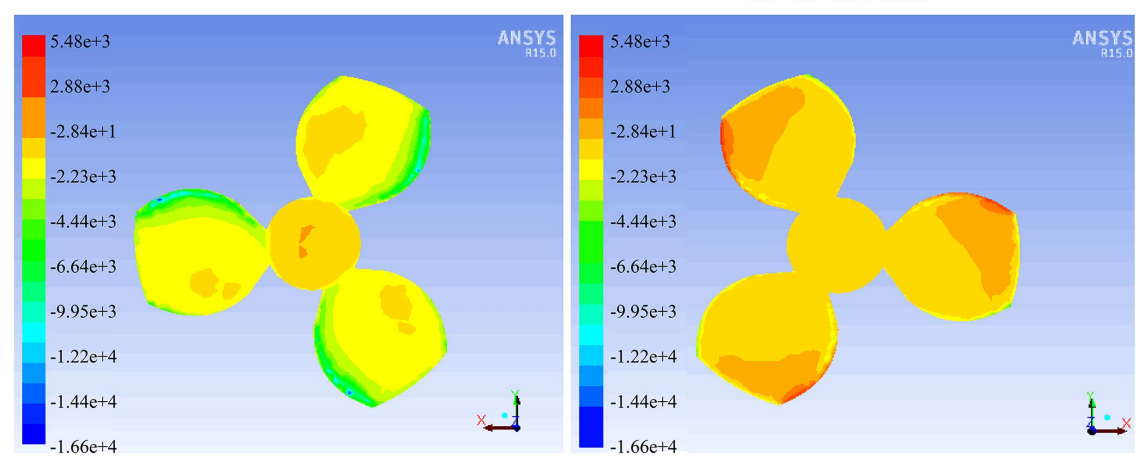

(b) The rotational velocity at $1000 \mathrm{rpm}$

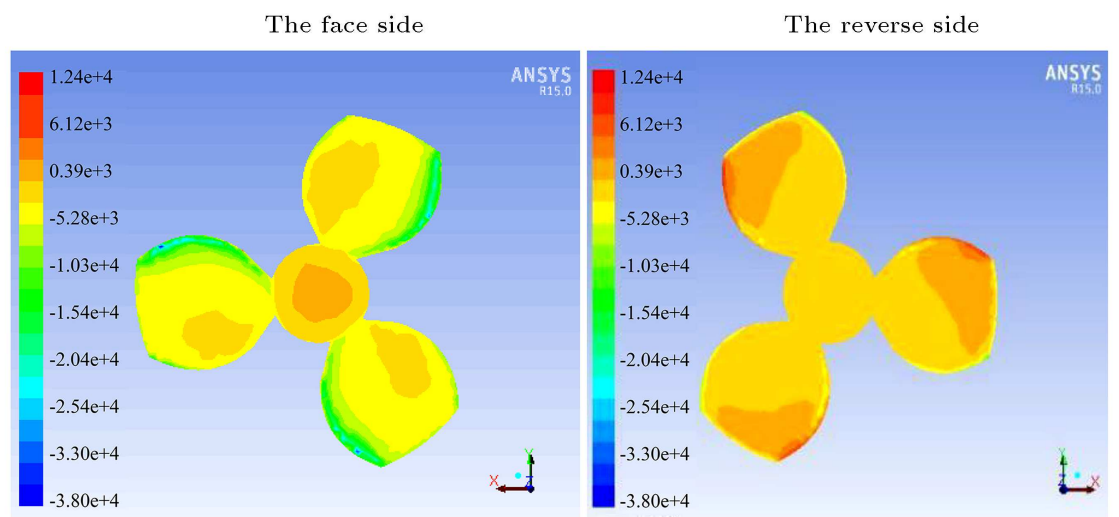

(c) The rotational velocity at $1500 \mathrm{rpm}$

The face side

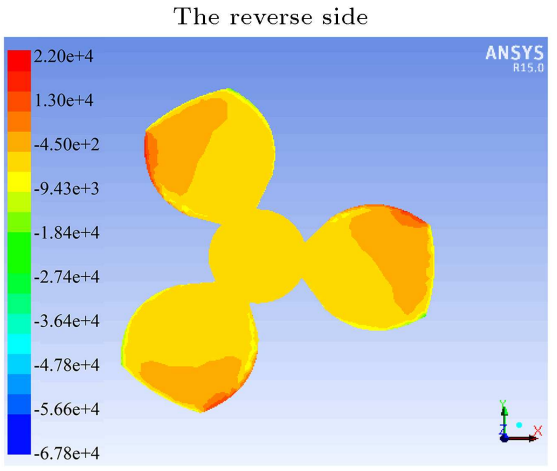

(d) The rotational velocity at $2000 \mathrm{rpm}$

Figure 13. The pressure contours with different rotational velocities. 


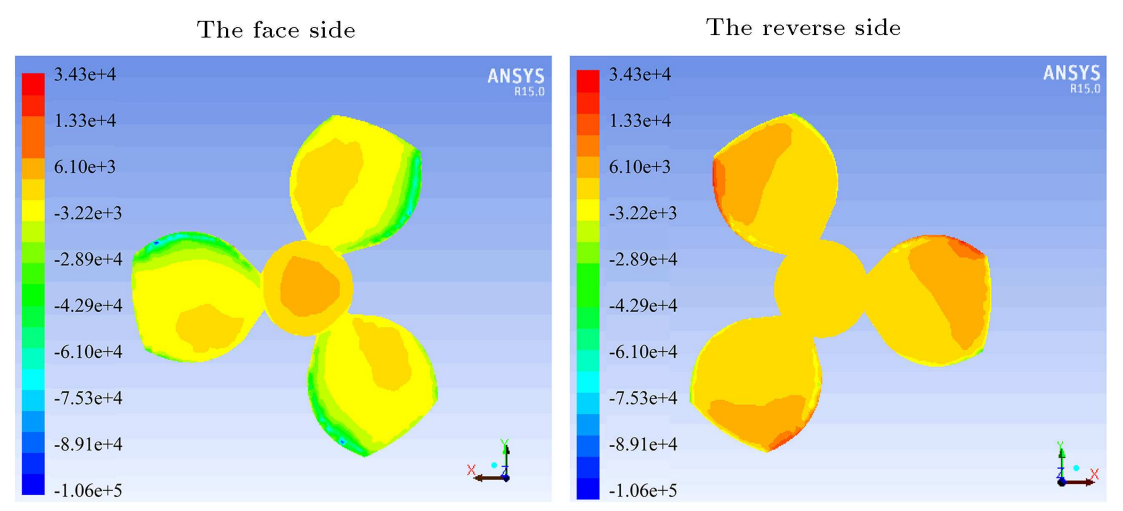

(e) The rotational velocity at $2500 \mathrm{rpm}$

Figure 13. The pressure contours with different rotational velocities (continued).
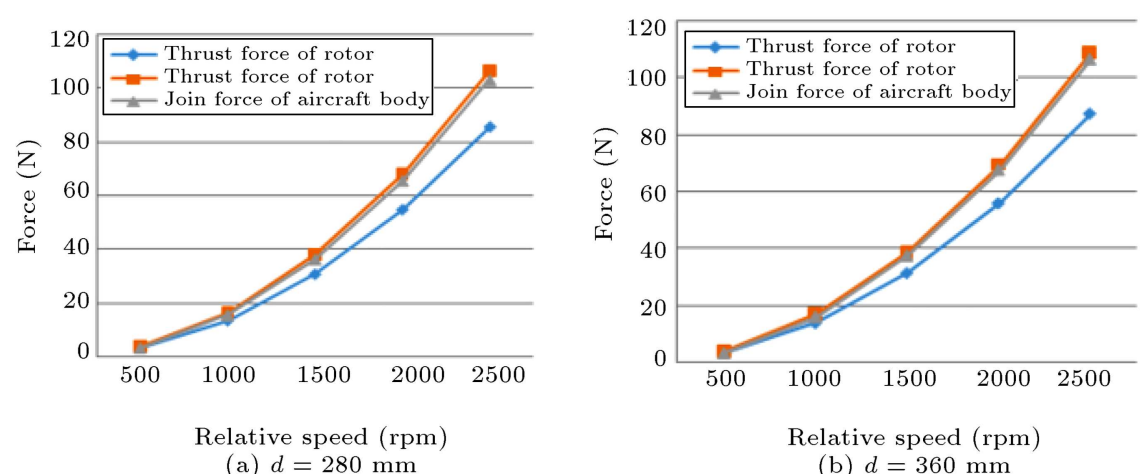

Figure 14. The force characteristics at different lateral distances and rotational velocities and the same longitudinal distance.
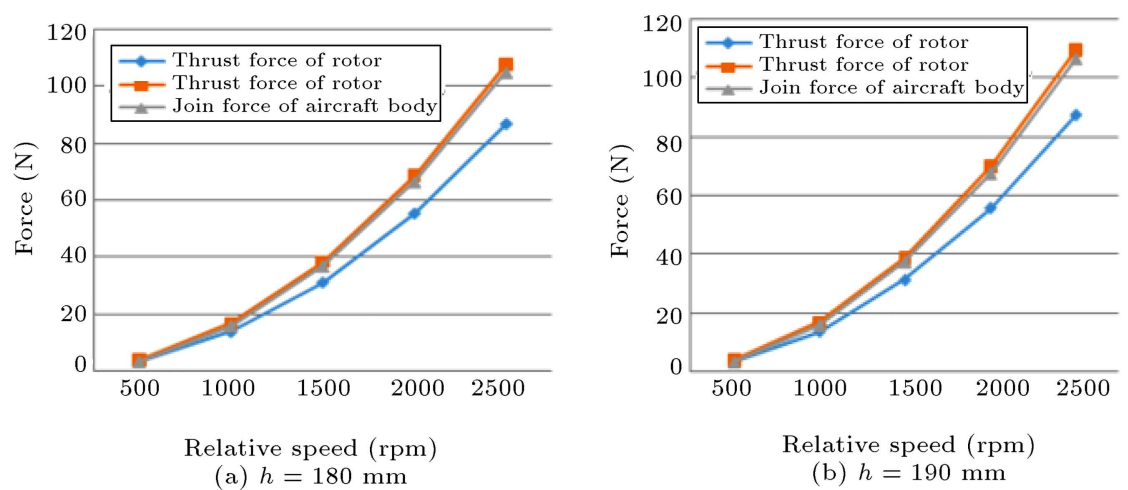

Figure 15. The force characteristics at different longitudinal distances and rotational velocities and the same lateral distance.

It can be easily concluded that all the forces increase as the rotational velocity rises, and the join force of rotors in ducts, which is a bit larger than that of the body, is much larger than the thrust force of single rotors. The resistances are created during the navigation so that the join force of the body is smaller than that of the rotors in ducts, and the duct architecture can improve the flow characteristics, which results in the thrust force differences between the rotors with ducts and the ones without them.

The lateral distance was kept at $320 \mathrm{~mm}$ as well as the longitudinal distance at $180 \mathrm{~mm}$ and $190 \mathrm{~mm}$; the condition changes of rotational velocities was the same as the above simulation. Then the force characteristics were obtained as shown in Figure 15.

It is obviously seen from Figure 15 that the simulation results are nearly same as those above. It can also be concluded that the effects of different rotational velocities on thrust force are not relative to the lateral and longitudinal distances. With the increase of the distances, the force characteristics showed a constant rising trend. 
Table 2. The results of the orthogonal test and kriging fitting.

\begin{tabular}{cccccccc}
\hline Test no. & $\boldsymbol{d} /(\mathbf{m m})$ & $\boldsymbol{h} /(\mathbf{m m})$ & $\boldsymbol{n} /(\mathbf{r p m})$ & $\begin{array}{c}\text { Simulation } \\
\text { result }\end{array}$ & $\begin{array}{c}\text { Fitting } \\
\text { result }\end{array}$ & Error & $\begin{array}{c}\text { Relative } \\
\text { error }\end{array}$ \\
\hline 1 & 280 & 180 & 500 & 3.9932 & 4.2546 & 0.2614 & 0.0655 \\
2 & 280 & 190 & 1000 & 16.0574 & 15.2802 & -0.7772 & -0.0484 \\
3 & 280 & 200 & 1500 & 38.0499 & 39.4275 & 1.3776 & 0.0362 \\
4 & 280 & 210 & 2000 & 66.5626 & 65.4332 & -1.1294 & -0.0170 \\
5 & 280 & 220 & 2500 & 105.0224 & 106.5510 & 1.5286 & 0.0146 \\
6 & 320 & 180 & 1000 & 16.0066 & 15.7275 & -0.2791 & -0.0174 \\
7 & 320 & 190 & 1500 & 36.7329 & 37.3332 & 0.6003 & 0.0163 \\
8 & 320 & 200 & 2000 & 69.6059 & 71.2332 & 1.6273 & 0.0234 \\
9 & 320 & 210 & 2500 & 99.2628 & 100.9866 & 1.7238 & 0.0174 \\
10 & 320 & 220 & 500 & 3.6175 & 3.3906 & -0.2269 & -0.0627 \\
11 & 360 & 180 & 1500 & 38.6902 & 39.1862 & 0.4960 & 0.0128 \\
12 & 360 & 190 & 2000 & 70.4142 & 69.3020 & -1.1122 & -0.0158 \\
13 & 360 & 200 & 2500 & 108.7905 & 110.5102 & 1.7197 & 0.0158 \\
14 & 360 & 210 & 500 & 3.9676 & 3.1883 & -0.7793 & -0.1964 \\
15 & 360 & 220 & 1000 & 17.0544 & 17.5749 & 0.5205 & 0.0305 \\
16 & 400 & 180 & 2000 & 65.6276 & 66.2490 & 0.6214 & 0.0095 \\
17 & 400 & 190 & 2500 & 112.4705 & 111.6659 & -0.8046 & -0.0072 \\
18 & 400 & 200 & 500 & 4.0367 & 3.8214 & -0.2153 & -0.0533 \\
19 & 400 & 210 & 1000 & 17.2187 & 16.4154 & -0.8033 & -0.0467 \\
20 & 400 & 220 & 1500 & 36.0556 & 36.5701 & 0.5145 & 0.0143 \\
21 & 440 & 180 & 2500 & 112.3139 & 111.1944 & -1.1195 & -0.0100 \\
22 & 440 & 190 & 500 & 4.2729 & 3.1545 & -1.1184 & -0.2617 \\
23 & 440 & 200 & 1000 & 16.9722 & 16.1993 & -0.7729 & -0.0455 \\
24 & 440 & 210 & 1500 & 38.4892 & 38.2791 & -0.2101 & -0.0055 \\
25 & 440 & 220 & 2000 & 66.3356 & 65.2154 & -1.1202 & -0.0169 \\
\hline & & & & & & &
\end{tabular}

\section{Optimization design and comparison}

In this section, based on the simulation results presented in last section, an optimization design of different architecture layouts underwater is accomplished with the help of orthogonal test, Kriging model and PSO algorithm.

\subsection{Orthogonal test}

The orthogonal test [21] is designed to reduce the number of the simulations aimed at certain factors and levels. In this analysis, there are three factors which include lateral distance, longitude distance and rotational velocity, and there are five levels in each factor. This implies that the simulation will be simplified $5^{3}-25=100$ times more, if an $L_{25}$ orthogonal list is herein employed.

\subsection{Kriging model}

The kriging model is a method of meta model based on the space correlation function, which can lead to the relationship between the spatial position and relevance of the data points obtained from the simulations, in order to receive the minimal variance.

According to the simulation results and based on

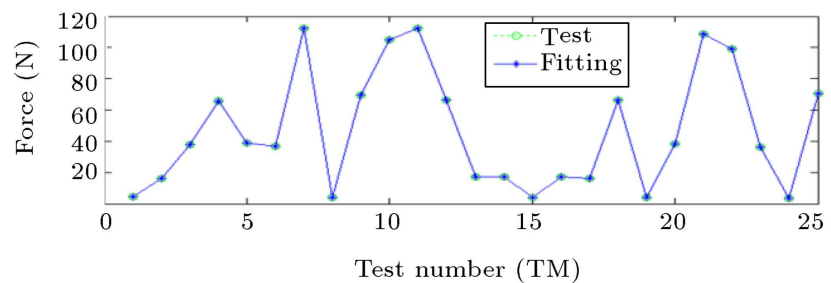

Figure 16. The comparison between the simulation and fitting results.

orthogonal test, a kriging model [22-24] is established, which adopts the output force of the tail propulsion ducts as the objective function with the help of constant regression model. The simulation arrangements based on this orthogonal test and the results of each simulation are depicted in Table 2 .

The comparison between the simulation and fitting results of kriging model is clearly depicted in Table 2 and Figure 16, they are perfectly close except the 22th simulation, which means the global error between them is quite small.

\subsection{PSO algorithm}

PSO (Particle Swarm Optimization) [25-27] is a type 
Table 3. The calculating parameters of Particle Swarm Optimization (PSO) algorithm.

\begin{tabular}{lcccc}
\hline Items & $\begin{array}{c}\text { Particle } \\
\text { swarm number }\end{array}$ & $\begin{array}{c}\text { Learning } \\
\text { factors }\end{array}$ & $\begin{array}{c}\text { Inertia } \\
\text { weight }\end{array}$ & $\begin{array}{c}\text { Iteration } \\
\text { step }\end{array}$ \\
\hline Values & 50 & 2 & 0.5 & 200 \\
\hline
\end{tabular}

Table 4. The optimal solutions of each factor.

\begin{tabular}{cccc}
\hline Factors & $\begin{array}{c}\text { Lateral } \\
\text { distance }\end{array}$ & $\begin{array}{c}\text { Longitudinal } \\
\text { distance }\end{array}$ & $\begin{array}{c}\text { Rotational } \\
\text { velocity }\end{array}$ \\
\hline Optimal solutions & $363.2321 \mathrm{~mm}$ & $196.5593 \mathrm{~mm}$ & $1732 \mathrm{rpm}$ \\
\hline
\end{tabular}

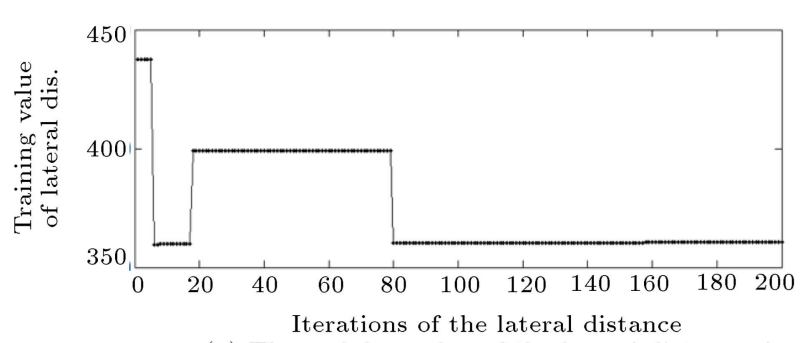

(a) The training value of the lateral distance $d$

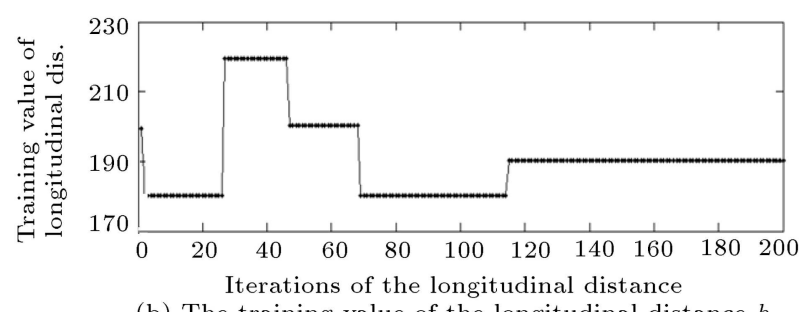

(b) The training value of the longitudinal distance $h$

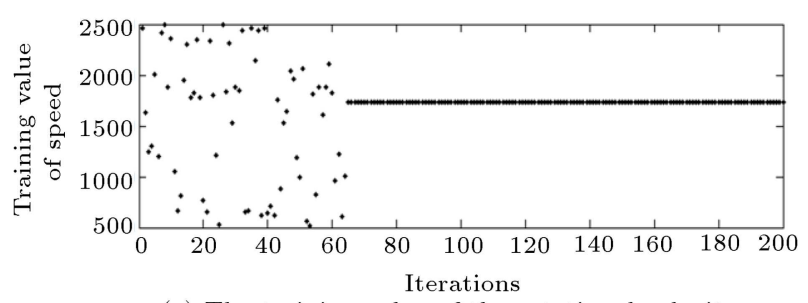

(c) The training value of the rotational velocity $n$

Figure 17. The training values of Particle Swarm Optimization (PSO) algorithm.

of evolution algorithm similar to iteration and genetic algorithm, which can help figure out the global optimal solution. Using the PSO algorithm, the optimization design is accomplished with MATLAB based on the kriging model designed in last section. The calculating parameters are selected as shown in Table 3 ; the training values of PSO are shown in Figure 17 and the optimal solutions of each factor obtained by PSO are shown in Table 4.

\subsection{Optimization comparison}

A Fluent simulation based on a new model designed according to the optimal solutions, $d=363.2321 \mathrm{~mm}$, $h=196.5593 \mathrm{~mm}$, is accomplished with rotational velocity at 500 and $1000 \mathrm{rpm}$. The optimization comparison of join forces is depicted in Figure 18.

The obvious conclusion is that the join force reaches the maximum level when the selected lateral distance falls into optimal solution under the conditions of certain rotational velocity and longitudinal distance, and it is true of the circumstance of the longitudinal distance. It is true that faster rotational velocity can provide higher thrust force, but faster velocity means higher requirements of the architecture. According to the optimal solutions, the rotational velocity $n=1732 \mathrm{rpm}$ is the most suitable value that can not only provide enough thrust force but also protect the whole architecture.

\section{Conclusion}

The conclusions can be drawn as follows:

1. The overall layout of the architecture and power system has been designed based on the particularities of the water-air cross-domain Unmanned Aerial Vehicle (UAV), and the mathematical and dynamic models are also designed;

2. The fluid characteristics in submerged condition are analyzed by the Computational Fluid Dynamics (CFD) simulation, which mainly aims at the effects on thrust forces resulting from the differences in lateral distance, longitudinal distance and rotational velocity. According to the pressure contours of the body and rotors, the parts which need reinforcing are confirmed. It is concluded that the join force will reach the maximum level when the selected lateral distance is $360 \mathrm{~mm}$ and the selected longitudinal distance is $200 \mathrm{~mm}$. It is also proved that the join force will grow with the increase of the rotational velocity at certain lateral and longitudinal distances;

3. The architecture in the submerged condition is optimized based on the PSO algorithm: The orthogonal test is designed and accomplished, upon which a series of simulations are finished; the kriging model is built according to the results of 


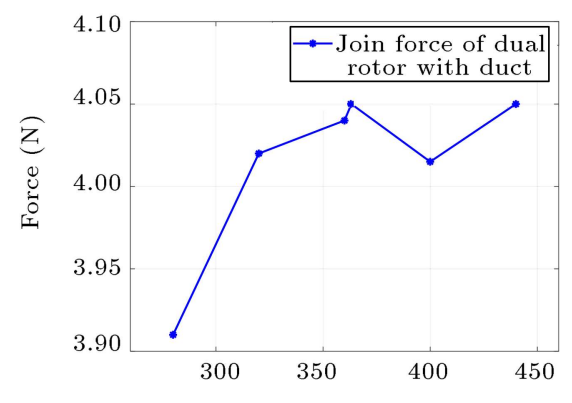

Lateral distance of dual ducts $(\mathrm{mm})$

(a) Join forces under a certain longitudinal distance and a rotational velocity at $500 \mathrm{rpm}$ with diffrent lateral distances

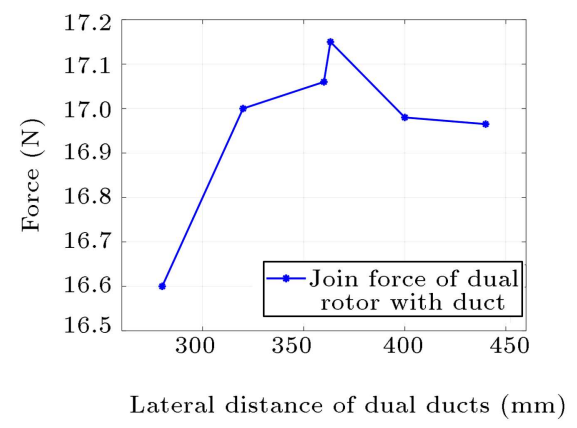

(b) Join forces under a certain longitudinal distance and a rotational velocity at $1000 \mathrm{rpm}$ with different lateral distances

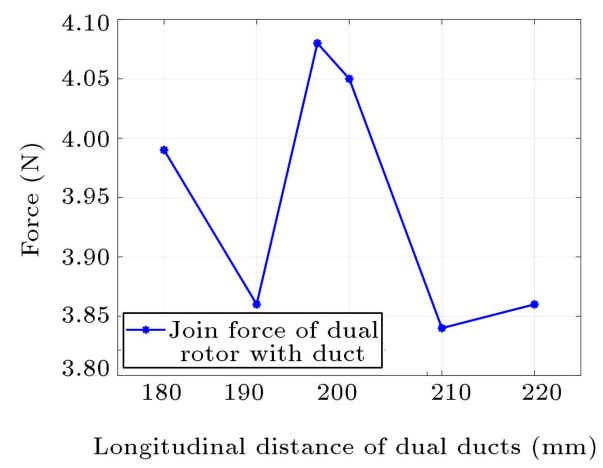

(c) Join forces under a certain lateral distance and a rotational velocity at $500 \mathrm{rpm}$ with different longitudinal distances

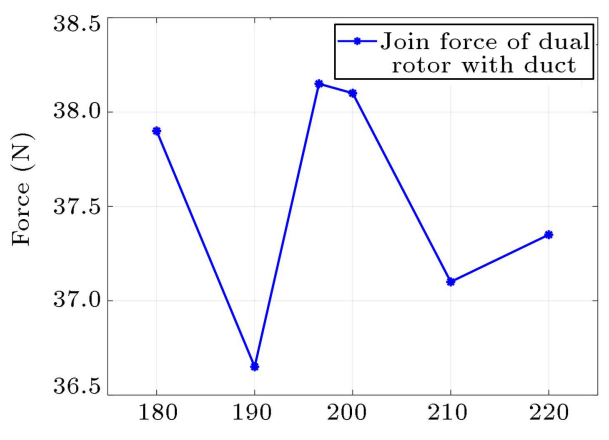

Longitudinal distance of dual ducts $(\mathrm{mm})$

(d) Join forces under a certain lateral distance and a rotational velocity at $1000 \mathrm{rpm}$ with different longitudinal distances

Figure 18. The optimization comparison of join forces. the above mentioned simulations; and the PSO algorithm is applied on the basis of the simulation and fitting results, and according to the kriging model to figure out the optimal solutions in which the selected lateral distance is $363.2321 \mathrm{~mm}$, the selected longitudinal distance is $196.5593 \mathrm{~mm}$ and the selected rotational velocity is $1732 \mathrm{rpm}$. On the basis of the results of optimization comparison, all the optimal solutions are proved to be reasonable.

\section{Acknowledgment}

This project is supported by Jilin Province Key Science and Technology R\&D Project under Grant No: 20180201040GX, National Natural Science Foundation of China under Grant No: 51505174, Scientific and Technological Development Program of Jilin Province of China under Grant No: 20170101206JC, Foundation of Education Bureau of Jilin Province under Grant No: JJKH20170789KJ, research fund for the doctoral program of higher education of China under Grant No: 20130061120038, national key research and development program of China under Grant No: 2017 YFC0602002.

\section{References}

1. Drews, P.L.J., Neto, A.A., and Campos, M.F.M. "A survey on aerial submersible vehicles", Proc. IEEE/OES Oceans Int. Conf., pp. 1-7 (2009). https://www.researchgate.net/profile/Paulo_Drews$\mathrm{Jr} /$ publicat ion/263314909_A_Surv ey_on_Aerial_ Submersible_Vehicles/links/0a85e53a8ace0d663900 0000.pdf

2. Yang, X., Wang, T., Liang, J., et al. "Survey on the novel hybrid aquaticaerial amphibious aircraft: Aquatic unmanned aerial vehicle (AquaUAV)", Progress in Aerospace Sciences, 74, pp. 131-151 (2015).

3. Gao, A. and Techet, A.H. "Design considerations for a robotic flying fish", Oceans'11 MTS/IEEE KONA, pp. 1-8 (2011). DOI: $10.23919 /$ OCEANS.2011.6107039 https://ieeexplore.ieee.org/document/6107039

4. Fabian, A., Feng, Y., and Swartz, E., Hybrid Aerial Underwater Vehicle, Lexington, USA: MIT Lincoln Lab (2012).

5. Liang, J.H., Yao, G.C., Wang, T.M., et al. "Wing load investigation of the plunge-diving locomotion of a gannet Morus inspired submersible aircraft", Science China Technological Sciences, 57(2), pp. 390-402 (2014).

6. Siddall, R. and Kovač, M. "Launching the AquaMAV: bioinspired design for aerial-aquatic robotic platforms", Bioinspiration \& Biomimetics, 9(3), pp. $1-18$ (2014). 
7. Siddall, R., Ancel, A.O., and Kovač, M. "Wind and water tunnel testing of a morphing aquatic micro air vehicle", Interface Focus, 7(1), pp. 1-15 (2017).

8. Chen, Y., Helbling, E.F., Gravish, N., et al. "Hybrid aerial and aquatic locomotion in an at-scale robotic insect", International Conference on Intelligent Robots and Systems, IEEE, pp. 331-338 (2015).

9. Chen, Y., Wang, H., Helbling, E.F., et al. "A biologically inspired, flapping-wing, hybrid aerial-aquatic microrobot", Science Robotics, 2(11), pp. 1-11 (2017).

10. Alzu'Bi, H., Akinsanya, O., Kaja, N., et al. "Evaluation of an aerial quadcopter power-plant for underwater operation", 10th International Symposium on Mechatronics and Its Applications (ISMA), IEEE, pp. 1-4 (2015).

11. Alzu'Bi, H., Mansour, I., and Rawashdeh, O. "Loon copter: Implementation of a hybrid unmanned aquaticaerial quadcopter with active buoyancy control", Journal of Field Robotics, 3, pp. 1-15 (2018).

12. Maia, M.M., Soni, P., and Diez, F.J. "Demonstration of an aerial and submersible vehicle capable of flight and underwater navigation with seamless air-water transition", Compute Science, pp. 1-9 (2015).

13. Villegas, A., Mishkevich, V., Gulak, Y., et al. "Analysis of key elements to evaluate the performance of a multirotor unmanned aerial aquatic vehicle", Aerospace Science and Technology, 70, pp. 412-418 (2017).

14. Mercado, D., Maia, M., and Diez, F.J. "Aerialunderwater systems, a new paradigm in unmanned vehicles", Journal of Intelligent \& Robotic Systems, 95(10), pp. 229-238 (2019).

DOI: $10.1007 / \mathrm{s} 10846-018-0820-\mathrm{x}$

15. Drews, P.L.J, Neto, A.A., and Campos, M.F.M. "Hybrid unmanned aerial underwater vehicle: Modeling and simulation", International Conference on Intelligent Robots \& Systems, IEEE, pp. 4637-4642 (2014).

16. Rosa, R.T.S., Evald, P.J.D.O., and Drews, P.L.J. "A comparative study on sigma-point Kalman filters for trajectory estimation of hybrid aerial-aquatic vehicles", International Conference on Intelligent Robots and Systems (IROS), IEEE, pp. 7460-7465 (2018).

17. Qi, D., Feng, J., and Li, Y. "Dynamic model and ADRC of a novel water-air unmanned vehicle for water entry with in-ground effect", Journal of Vibroengineering, 18(6), pp. 3743-3756 (2016).

18. Ma, Z.C., Feng, J.F., and Yang, J. "Research on vertical air water trans-media control of hybrid unmanned aerial underwater vehicles based on adaptive sliding mode dynamical surface control", International Journal of Advanced Robotic Systems, 15(2), pp. 1-10 (2018).
19. Lu, D., Xiong, C., Lyu, B., et al. "Multi-mode hybrid aerial underwater vehicle with extended endurance", OCEANS-MTS/IEEE Kobe Techno-Oceans (OTO), IEEE, pp. 1-7 (2018)

20. Ferziger, J.H. and Peric, M., Computational Methods for Fluid Dynamics, 3rd Edn., Springer-Verlag Berlin Heidelberg, pp. 71-90, New York, USA (2002).

21. Antony, J., Design of Experiments for Engineers and Scientists, 2nd Edn, pp. 29-42, Elsevier Science \& Technology Books, Amsterdam, Holland (2003).

22. Xiao, Q., Wang, L., and Xu, H. "Application of kriging models for a drug combination experiment on lung cancer", Statistics in Medicine, 38(2), pp. 236-246 (2019).

23. Kim, K. and June, J. "Multiobjective optimization for a plasmonic nanoslit array sensor using Kriging models", Applied Optics, 56(21), pp. 5838-5843 (2017).

24. Park, T., Yum, B., Hung, Y., et al. "Robust Kriging models in computer experiments", Journal of the Operational Research Society, 67(4), pp. 644-653 (2016).

25. Kaveh, A. and Nasrollahi, A. "Charged system search and particle swarm optimization hybridized for optimal design of engineering structures", Scientia Iranica, 21(2), pp. 295-305 (2014).

26. Li, C., Zhai, R., Liu, H., et al. "Optimization of a heliostat field layout using hybrid PSO-GA algorithm", Applied Thermal Engineering, 128, pp. 33-41 (2018).

27. Nobile, M.S., Cazzaniga, P., Besozzi, D., et al. "Fuzzy self-tuning PSO: A settings-free algorithm for global optimization", Swarm and Evolutionary Computation, 39, pp. 70-85 (2018).

\section{Biographies}

Yanli Chen received the $\mathrm{PhD}$ degree in Mechatronic Engineering from Jilin University, Changchun, China, in 2012. He was a postdoctoral research worker with solid geophysics from Jilin University in 2016. He is a currently Associate Professor and his research interests include: cooperatively pursue and intelligent control of multiple autonomous underwater vehicles, fluid power transmission and control.

Jingchun Qin received the BE degree in Automobile Engineering from Jilin University, Changchun, China, in 2016. He is currently a master student within Jilin University, Changchun, China. His current research interests include: cooperatively pursue and intelligent control of multiple autonomous underwater vehicles, fault tolerant control and modern fault diagnosis, optimizing and controller design.

Hua-peng Sun received the BE degree in Mechanical Engineering from Shandong University of Technology, Jinan, China, in 2014. He is currently a master student within Jilin University, Changchun, China. 
His current researches interests include cooperatively pursue and intelligent control of multiple autonomous underwater vehicles, fault tolerant control and modern fault diagnosis, optimizing and controller design.

Tao Shang received the $\mathrm{PhD}$ degree in Mechatronic Engineering from Jilin University, Changchun, China, in 2004. His current research interests include: cooperatively pursue and intelligent control of multiple autonomous underwater vehicles, fluid power transmission and control.

Xinge Zhang received the $\mathrm{PhD}$ degree in Mechatronic Engineering from Harbin institute of technology,
Harbin, China, 2012. He is a currently Associate Professor and his research interests include: cooperatively pursue and intelligent control of multiple autonomous underwater vehicles, fluid power transmission and control.

Yi $\mathrm{Hu}$ received the $\mathrm{BE}$ degree in Mechanical Engineering from Nanjing Agricultural University, Nanjing, China, in 2016. He is currently a master student within Jilin University, Changchun, China. His current researches interests include cooperatively pursue and intelligent control of multiple autonomous underwater vehicles, fault tolerant control and modern fault diagnosis, optimizing and controller design. 